\title{
Article \\ NGS Analysis Confirms Common TP53 and RB1 Mutations, and Suggests MYC Amplification in Ocular Adnexal Sebaceous Carcinomas
}

\author{
Cornelia Peterson ${ }^{1}$ (D), Robert Moore ${ }^{2}$, Jessica L. Hicks ${ }^{2}$, Laura A. Morsberger 2,3,4, Angelo M. De Marzo ${ }^{2,5,6}$, \\ Ying Zou ${ }^{2,3,4}$, Charles G. Eberhart ${ }^{2,7, *}$ and Ashley A. Campbell ${ }^{7, *}$
}

check for

updates

Citation: Peterson, C.; Moore, R.; Hicks, J.L.; Morsberger, L.A.; De Marzo, A.M.; Zou, Y.; Eberhart, C.G.; Campbell, A.A. NGS Analysis Confirms Common TP53 and RB1 Mutations, and Suggests MYC Amplification in Ocular Adnexal Sebaceous Carcinomas. Int. J. Mol. Sci. 2021, 22, 8454. https://doi.org/ $10.3390 /$ ijms 22168454

Academic Editor: Robert M. Verdijk

Received: 12 July 2021

Accepted: 4 August 2021

Published: 6 August 2021

Publisher's Note: MDPI stays neutral with regard to jurisdictional claims in published maps and institutional affiliations.

Copyright: (c) 2021 by the authors Licensee MDPI, Basel, Switzerland. This article is an open access article distributed under the terms and conditions of the Creative Commons Attribution (CC BY) license (https:// creativecommons.org/licenses/by/ $4.0 /)$.
1 Department of Molecular and Comparative Pathobiology, The Johns Hopkins University School of Medicine, Baltimore, MD 21205, USA; cpeter52@jhmi.edu

2 Department of Pathology, The Johns Hopkins University School of Medicine, Baltimore, MD 21205, USA; robert.f.moore@gmail.com (R.M.); jbeckman@jhmi.edu (J.L.H.); lmorsber@jhmi.edu (L.A.M.); ademarz@jhmi.edu (A.M.D.M.); yzou19@jhmi.edu (Y.Z.)

3 Clinical Cytogenetics Laboratory, The Johns Hopkins University School of Medicine, Baltimore, MD 21205, USA

4 Johns Hopkins Genomics, The Johns Hopkins University School of Medicine, Baltimore, MD 21205, USA

5 Sidney Kimmel Comprehensive Cancer Center, The Johns Hopkins University School of Medicine, Baltimore, MD 21205, USA

6 The Brady Urological Research Institute, The Johns Hopkins University School of Medicine, Baltimore, MD 21205, USA

7 Department of Ophthalmology, The Johns Hopkins University School of Medicine, Baltimore, MD 21205, USA

* Correspondence: ceberha@jhmi.edu (C.G.E.); acampb23@jhmi.edu (A.A.C.); Tel.: +1-410-502-5185 (C.G.E.); +1-410-955-1112 (A.A.C.)

Abstract: Ocular adnexal (OA) sebaceous carcinomas generally demonstrate more aggressive clinical and histopathological phenotypes than extraocular cases, but the molecular drivers implicated in their oncogenesis remain poorly defined. A retrospective review of surgical and ocular pathology archives identified eleven primary resection specimens of OA sebaceous carcinomas with adequate tissue for molecular analysis; two extraocular cases were also examined. Next-generation sequencing was used to evaluate mutations and copy number changes in a large panel of cancer-associated genes. Fluorescence in situ hybridization (FISH) confirmed MYC copy number gain in select cases, and immunohistochemistry to evaluate MYC protein expression. The commonest mutations occurred in TP53 (10/13) and RB1 (7/13). Additional mutations in clinically actionable genes, or mutations with a frequency of at least 25\%, included the NF1 (3/12), PMS2 (4/12), ROS1 (3/12), KMT2C (4/12), MNX1 (6/12), NOTCH1 (4/12), PCLO (3/12), and PTPRT (3/12) loci. Low level copy number gain suggestive of amplification of the MYC locus was seen in two cases, and confirmed using FISH. MYC protein expression, as assessed by immunohistochemistry, was present in almost all sebaceous carcinoma cases. Our findings support the concept that alterations in TP53 and RB1 are the commonest alterations in sebaceous carcinoma, and suggest that MYC may contribute to the oncogenesis of these tumors.

Keywords: sebaceous carcinoma; ocular adnexal tumor; next-generation sequencing; MYC

\section{Introduction}

Nearly $40 \%$ of sebaceous carcinomas arise from the sebaceous glands of the periocular region, where they represent approximately $5 \%$ of all epithelial eyelid malignancies [1-4]. These ocular adnexal (OA) sebaceous carcinomas can have variable presentations, including cases resembling benign inflammatory lesions, such as blepharoconjunctivitis or chalazion, or other types of malignancy, often leading to a delay in diagnosis and surgical intervention $[3,5,6]$. Sebaceous carcinomas in this region are relatively aggressive, and tumor recurrence has been demonstrated in $18 \%$ of cases, metastasis in $7-21 \%$, and mortality 
in 6-20\% $[4,7,8]$. Intraepithelial or pagetoid spread, particularly in the conjunctiva, occurs in approximately $50 \%$ of OA sebaceous carcinomas, and is thought to contribute to a more aggressive phenotype than that seen in extraocular tumors [7].

A number of mutations have been identified in sebaceous carcinoma, but molecular drivers remain incompletely understood. The low incidence of $0.16 / 100,000$ person-years for sebaceous carcinoma in the US, as well as the small size of many biopsy specimens, means that it is difficult for a single institution to accumulate large cohorts with excess tissue for molecular analysis. [9] However, several studies have identified mutations in tumor suppressor genes, including TP53 and RB1, and p16 expression has been implicated as a robust immunohistochemical marker for these tumors [10-19]. High-risk human papillomavirus (HPV), whose oncogenes encode well-characterized inhibitors of p53 and $\mathrm{Rb}$, has been detected in up to $18 \%$ of $\mathrm{OA}$ sebaceous carcinomas without concurrent tumor suppressor mutations, and additional studies have demonstrated overexpression of miRNAs that influence the p53 suppressor complex [6,11,20-22].

Sebaceous proliferations, most commonly benign sebaceous adenomas or sebaceomas, but also sebaceous carcinomas, can occur in association with visceral malignancies in Muir-Torre Syndrome (MTS), a phenotypic subset of hereditary non-polyposis colon cancer syndrome (HNPCC), or Lynch syndrome [7,23]. Affected patients demonstrate microsatellite instability (MSI) and autosomal dominant loss-of-function mutations in genes encoding DNA mismatch repair (MMR) proteins, including MLH1, MSH2, and less frequently, MSH6, PMS1, and PMS2 [7,24-32]. However, loss of MMR protein expression and/or MSI occurs more commonly in extraocular than OA sebaceous carcinomas [7,33].

While mutations involving tumor suppressor complexes and DNA repair mechanisms have been documented, further elucidation of the molecular drivers in sebaceous carcinoma oncogenesis could provide a more targeted treatment approach to minimize the need for aggressive surgical resection, currently challenged by tumor multicentricity, skip lesions, and pernicious intraepithelial spread. The objectives of the current study were to identify molecular drivers of OA sebaceous carcinoma utilizing Next-generation sequencing (NGS), and to validate novel alterations using appropriate techniques.

\section{Results}

\subsection{Clinicopathologic Characteristics}

Eleven primary sebaceous carcinoma specimens from OA sites with enough tissue for NGS analysis were identified from retrospective review, along with 2 from extraocular sites. In this cohort, tumors arose in 6 males and 7 females, all of whom were Caucasian. The mean age of patients at clinical presentation was 72 years (range 43-90). Seven patients reported a history of prior malignancy, and 1 had a diagnosis of Muir-Torre syndrome. OA tumors were predominantly localized to the upper lid $(n=9)$, but were also identified in the lower lid $(n=2)$. None of the tumors were associated with local or distant metastases.

Histological features of the tumors included combined intraepithelial and subepithelial involvement $(n=6)$, intraepithelial involvement alone $(n=1)$, and subepithelial involvement alone $(n=2)$. Based on the AJCC 8 th edition TMN classification, 11 cases were classified as Tis/T1 and 2 as T2. The mean size of the tumors was $7.5 \mathrm{~mm}$. Clinicopathologic characteristics for each case are shown in Table 1. 
Table 1. Clinicopathologic characteristics of individual cases (OA, ocular adnexal, EO, extraocular)t).

\begin{tabular}{|c|c|c|c|c|c|c|c|c|}
\hline $\begin{array}{c}\text { Case } \\
\text { Number }\end{array}$ & Sex & $\begin{array}{c}\text { Age } \\
\text { (years) }\end{array}$ & $\begin{array}{l}\text { Tumor } \\
\text { Type }\end{array}$ & $\begin{array}{l}\text { Tumor } \\
\text { Location }\end{array}$ & $\begin{array}{c}\text { Tumor } \\
\text { Laterality }\end{array}$ & $\begin{array}{c}\text { Epithelial } \\
\text { Involvement }\end{array}$ & T Stage & $\begin{array}{c}\text { History } \\
\text { of Malignancy }\end{array}$ \\
\hline 1 & $\mathrm{~F}$ & 54 & $\mathrm{OA}$ & Upper lid & Left & None & $\mathrm{T} 1$ & None \\
\hline 2 & $\mathrm{M}$ & 77 & $\mathrm{OA}$ & Upper lid & Right & Intraepithelial & $\mathrm{T} 1$ & None \\
\hline 3 & $\mathrm{M}$ & 83 & $\mathrm{OA}$ & Upper lid & Left & Combined & $\mathrm{T} 1$ & Non-cutaneous \\
\hline 4 & $\mathrm{~F}$ & 80 & $\mathrm{OA}$ & Upper lid & Right & Combined & $\mathrm{T} 1$ & None \\
\hline 5 & $\mathrm{M}$ & 87 & $\mathrm{OA}$ & Upper lid & Left & Combined & $\mathrm{T} 1$ & None \\
\hline 6 & $\mathrm{~F}$ & 60 & $\mathrm{OA}$ & Upper lid & Right & Combined & $\mathrm{T} 1$ & None \\
\hline 7 & $\mathrm{~F}$ & 82 & $\mathrm{OA}$ & Upper lid & Left & Combined & $\mathrm{T} 2$ & Cutaneous \\
\hline 8 & $\mathrm{M}$ & 83 & $\mathrm{OA}$ & Upper lid & Right & Subepithelial & $\mathrm{T} 1$ & Non-cutaneous \\
\hline 9 & $\mathrm{~F}$ & 90 & $\mathrm{OA}$ & Upper lid & Right & Subepithelial & $\mathrm{T} 2$ & None \\
\hline 10 & F & 55 & $\mathrm{OA}$ & Lower lid & Right & Combined & $\mathrm{T} 1$ & Cutaneous \\
\hline 11 & M & 43 & $\mathrm{OA}$ & Upper lid & Right & None & $\mathrm{T} 1$ & Non-cutaneous \\
\hline 12 & $\mathrm{~F}$ & 58 & $\mathrm{EO}$ & Lateral breast & Left & None & $\mathrm{T} 1$ & Multiple ${ }^{1}$ \\
\hline 13 & $\mathrm{M}$ & 87 & $\mathrm{EO}$ & $\begin{array}{l}\text { Post-auricular } \\
\text { neck }\end{array}$ & Left & None & $\mathrm{T} 1$ & Cutaneous \\
\hline
\end{tabular}

${ }^{1}$ MTS patient.

\subsection{Mutations in Sebaceous Carcinoma}

The NGS panel used detects mutations in 435 cancer-related genes, and for 64 of these loci, copy number variations (CNV) can also be identified. Due to limited DNA, a smaller 27 gene NGS panel with no copy number analysis was performed in Case11. Two hundred and forty-five mutations were identified in 205 genes in the 13 sebaceous carcinomas ( $2-46$ genes mutated per tumor, mean $15.9 \pm 12.9)$. All sebaceous carcinomas evaluated harbored at least 1 mutation in a clinically actionable gene, or in genes affecting pathways for which known therapeutic agents are available [34]. The mean number of genes with clinically actionable mutations in OA tumors was $4.4 \pm 3.4$ (range 1-13), while in extraocular tumors, the mean number of clinically actionable alterations was $5.5 \pm 0.7$ (range 5-6).

The most frequently encountered genetic alterations occurred in TP53 (10 mutations in 13 tumors, $76.9 \%$ ) and RB1 (7 mutations in 13 tumors, 53.8\%). Interestingly, while 10 out of 11 OA tumors $(90.9 \%)$ harbored TP53 mutations, neither of the 2 extraocular tumors demonstrated a mutation in this gene. All tumors $(7 / 7)$ that harbored an $R B 1$ mutation had TP53 computations, while 3/10 (30\%) of OA tumors harboring TP53 mutations were wild-type for RB1. Six of the 10 TP53 alterations were identified as missense mutations, 2 were nonsense mutations, and the remaining 2 were intronic substitutions. One of the 7 RB1 alterations $(14.3 \%)$ in the OA tumors was a deletion, $2 / 7$ (28.6\%) were nonsense mutations, $1 / 7(14.3 \%)$ was a missense mutation, and $3 / 7(42.9 \%)$ were intronic substitutions (see Table 2).

Additional clinically actionable alterations were noted in ABL1, FGFR2, IDH2, MLH1, PDGFRA, PTEN, RET, SMO, TSC1, and TSC2 in 1/13 tumors (7.7\%), BRCA2, MSH2, MSH6, MTOR, NTRK1, POLD1, PTCH2, and TERT in 1/12 tumors (8.3\%), EGFR, FGFR3, HRAS, and PIK3CA in 2/13 tumors (15\%), ATM, BRCA1, NTRK3, and PALB2 in 2/12 tumors (16.7\%), NF1 and ROS1 in 3/12 tumors (25\%), and PMS2 in $4 / 12$ tumors (33.3\%).

Other genes with an alteration frequency of at least $3 / 12(25 \%)$ included KMT2C in $4 / 12(33 \%)$, MNX1 in 6/12 (50\%), NOTCH1 in 4/12 (33\%), PCLO in 3/12 (25\%), and PTPRT in $3 / 12(25 \%)$. There were no clear differences in the frequency of these changes between $\mathrm{OA}$ and extraocular tumors. Both NOTCH1 mutations in OA tumors and 1/2 mutations in extraocular tumors were indels, while the remaining extraocular NOTCH1 alteration detected was a missense mutation. Mutations in KMT2C were missense mutations in $2 / 2$ OA tumors and deletions in $2 / 2$ extraocular tumors. None of these genes could be evaluated in Case 11, as they are not included in the limited NGS panel used. 
Table 2. NGS of sebaceous carcinoma (OA: ocular adnexal, EO: extraocular, NE: not evaluated, mutations highlighted in gray do not hold COSMIC annotations).

\begin{tabular}{|c|c|c|c|c|c|c|c|c|c|c|c|c|c|}
\hline Case Number & 1 & 2 & 3 & 4 & 5 & 6 & 7 & 8 & 9 & 10 & 11 & 12 & 13 \\
\hline \multicolumn{14}{|l|}{$\begin{array}{c}\text { Mutations in } \\
\text { Clinically } \\
\text { Actionable Genes }\end{array}$} \\
\hline$A B L 1$ & & & & & & & & & p.E197K & & & & \\
\hline ATM & & & p.Q2433Pfs"11 & & p.12669Yfs"6 & & & & & & & & \\
\hline BRCA1 & & p.K1487I & & & & & & & & p.R1726G & NE & & \\
\hline BRCA2 & & $\begin{array}{l}\text { p.L2510_Y25 } \\
\text { 11insKTCN }\end{array}$ & & & & & & & & & $\mathrm{NE}$ & & \\
\hline EGFR & & & & p.P772S & & & & & & & & & p.Q976Pfs"9 \\
\hline FGFR2 & & & & & & & & & & & & p.S702L & \\
\hline HRAS & & & & & & & & & & & & $\begin{array}{c}\text { p.P167Rfs" } 40, \\
\text { p.P167R }\end{array}$ & p.P167Rfs" 50 \\
\hline IDH2 & & & & & & & & & p.V335I & & & & \\
\hline MLH1 & & & & & & & & & & & & p.E694X & \\
\hline MSH 2 & & & & & & & & & & & $\mathrm{NE}$ & & $\begin{array}{l}\text { p.Q409Rfs*t, } \\
\text { p.Q409R, p.Q4409H, } \\
\text { p.I679T }\end{array}$ \\
\hline MSHG & & p.v526L & & & & & & & & & $\mathrm{NE}$ & & \\
\hline MTOR & & p.L93Qffs 28 & & & & & & & p.P677s & & $\mathrm{NE}$ & & \\
\hline$N F 1$ & & p.K1915T & & & & & & & & & $\mathrm{NE}$ & $\begin{array}{l}\text { p.I679Dfs*20, } \\
\text { p.C1924Wfs"3 }\end{array}$ & \\
\hline NTRK3 & & p.R169C & & & & & p.Y604H & & & & $\mathrm{NE}$ & & \\
\hline PALB2 & p.S417Y & p.R1117ffs"8 & & & & & & & & & $\mathrm{NE}$ & & \\
\hline PDGFRA & & p.E241X & & & & & & & & & & & \\
\hline PIK $3 C A$ & & & p.V101fs* & & & & & & & & & & \\
\hline PMS2 & & p.V397I & & & p.S418F & p.L2365fs"3 & & & p.L236delinsYLLKKIM & & $\mathrm{NE}$ & & \\
\hline POLD1 & & & & & & & & & & & NE & & $\begin{array}{l}\text { p.A242T } \\
\end{array}$ \\
\hline РТСH 2 & & & & & & & & & & & $\mathrm{NE}$ & p.G1023S, p.E48del & \\
\hline PTEN & & & & & & & & p.P281A & & & & & \\
\hline$R B 1$ & & p.? (Unknown) & $\mathrm{p}$ ? (Unknown) & & p.Q354EFs"5 & p.W75X, p.R358X & & p.? (Unknown) & p.E30X & p.R500I & & & \\
\hline RET & & & & & & & & & & & & p.A349V & \\
\hline ROS1 & & p.F1300L & & p.D2344N & p.L2337F & & & & & & $\mathrm{NE}$ & & \\
\hline SMO & & & & & & & & & & p.L23_G24insL & & & \\
\hline TERT & & & & & & $\begin{array}{l}\text { p.A279T } \\
\end{array}$ & & & & & $\mathrm{NE}$ & & \\
\hline TP53 & & p.R273C & p.G266R & p.? (Unknown) & p.C277F & p.R273C & p.G245s & p.L257P & p.? (Unknown) & p.E339X & p.R196* & & \\
\hline
\end{tabular}


Table 2. Cont.

\begin{tabular}{|c|c|c|c|c|c|c|c|c|c|c|c|c|c|}
\hline Case Number & 1 & 2 & 3 & 4 & 5 & 6 & 7 & 8 & 9 & 10 & 11 & 12 & 13 \\
\hline TSC1 & & & & & p.G274S & & & & & & $\mathrm{NE}$ & & \\
\hline TSC2 & & p.G440S & & & & & & & & & $\mathrm{NE}$ & & \\
\hline \multicolumn{14}{|l|}{$\begin{array}{c}\text { Genes with } \\
\text { Frequent } \\
\text { Mutations }(\geq 25 \%)\end{array}$} \\
\hline KMT2C & & & p.A1685S & & & & p.5888T & & & & $\mathrm{NE}$ & p.K2797Rfs"25 & p.K2797Rfs" 25 \\
\hline MNX1 & p.A134_G133insAA & p.A174del & p.A134_G135insAA & p.A134_G135insAA & & & p.A134_G135insAA & & p.A134_G135insAA & & $\mathrm{NE}$ & & \\
\hline Nотсн1 & & & & & & & & p.G1320Afs"124 & & p.Y550fs*0 & $\mathrm{NE}$ & p.R203C & $\begin{array}{l}\text { p.L1531Cfs* } 48 \\
\text { p.P1443Afs }\end{array}$ \\
\hline PCLO & & p.G1750E & p.P2128Q & & & & & & & & $\mathrm{NE}$ & p.E2925D & \\
\hline \multicolumn{14}{|l|}{ MYC Gain of Copy } \\
\hline Mean $\log _{2}$ Ratio & $<0.5$ & $\mathrm{NE}$ & $<0.5$ & 0.833 & 0.8959 & 0.5483 & 0.8178 & 1.3315 & 1.4416 & $<0.5$ & $\mathrm{NE}$ & 0.7733 & 0.6051 \\
\hline
\end{tabular}




\subsection{Copy Number Variations in Sebaceous Carcinoma}

Copy number gains (mean $\log _{2}$ ratio over 0.5 , but less than 1.3) were identified in 33 genes across 11 tumors (range: $3-14$, mean $6.6 \pm 3.5 \mathrm{CNVs} /$ tumor). Only one loss was identified among 11 tumors, which included the $A R$ locus. CNVs with a frequency of $\geq 18 \%$ included equivocal copy number gains in BAP1, CCND3, CCNE1, EZH2, MDM2, PIK3CA, and PMS2 each in 2/11 tumors (18.2\%), CDK4, KRAS, PTEN, and XPO1 each in $3 / 11$ tumors (27.3\%), AURKA and CDKN2A each in $4 / 11$ tumors (36.4\%), and CDKN2B and MYC each in 6/11 tumors (54.5\%) (see Supplemental Figure S1). Low level copy number gains suggestive of amplification (mean $\log _{2}$ ratio of 1.3 or greater) occurred only in MYC in $2 / 11$ tumors $(18.2 \%)$, both of which were OA. There were no significant differences between patient sex, age at presentation, tumor location, or laterality with respect to MYC CNV (see Table 3).

Table 3. MYC CNV status in sebaceous carcinoma and its relationship to clinicopathologic features (OA: ocular adnexal).

\begin{tabular}{|c|c|c|c|c|}
\hline Variable & $\begin{array}{c}\text { All Cases } \\
(n=11) \\
n(\%)\end{array}$ & $\begin{array}{c}\text { No MYC Copy Gain } \\
(n=3) \\
n(\%)\end{array}$ & $\begin{array}{c}\text { MYC Copy Gain } \\
(n=8) \\
n(\%)\end{array}$ & $p$ Value \\
\hline \multicolumn{5}{|l|}{ Sex } \\
\hline Male & $4(36)$ & $1(33)$ & $3(37)$ & \multirow{2}{*}{1.00} \\
\hline Female & $7(64)$ & $2(67)$ & $5(63)$ & \\
\hline $\begin{array}{l}\text { Age (years), } \\
\text { mean } \pm S D\end{array}$ & $73 \pm 13.8$ & $64 \pm 16.4$ & $76 \pm 12.3$ & 0.53 \\
\hline \multicolumn{5}{|l|}{ Tumor site } \\
\hline Ocular adnexal & $9(82)$ & $3(100)$ & $6(75)$ & \multirow[t]{2}{*}{1.00} \\
\hline Extraocular & $2(18)$ & $0(0)$ & $2(25)$ & \\
\hline \multicolumn{5}{|c|}{ Tumor location (OA: $n=9$ ) } \\
\hline Upper lid & $7(78)$ & $2(67)$ & $5(83)$ & \multirow[t]{2}{*}{1.00} \\
\hline Lower lid & $2(22)$ & $1(33)$ & $1(17)$ & \\
\hline \multicolumn{5}{|c|}{ Tumor laterality (OA: $n=9$ ) } \\
\hline Right & $5(56)$ & $1(33)$ & $4(67)$ & \multirow[t]{2}{*}{0.52} \\
\hline Left & $4(44)$ & $2(67)$ & $2(33)$ & \\
\hline
\end{tabular}

\subsection{MYC Fluorescence In Situ Hybridization (FISH)}

FISH analysis using probes that map to 8q24 confirmed increased MYC copy number in the two OA tumors with amplification suggested by NGS. Case 8 had MYC amplification in $76 \%$ of cells analyzed, with $55 \%$ of nuclei demonstrating five or more signals (see Figure 1). Case 9 had MYC amplification in $70 \%$ of cells analyzed, with $58 \%$ of nuclei demonstrating five or more signals. 


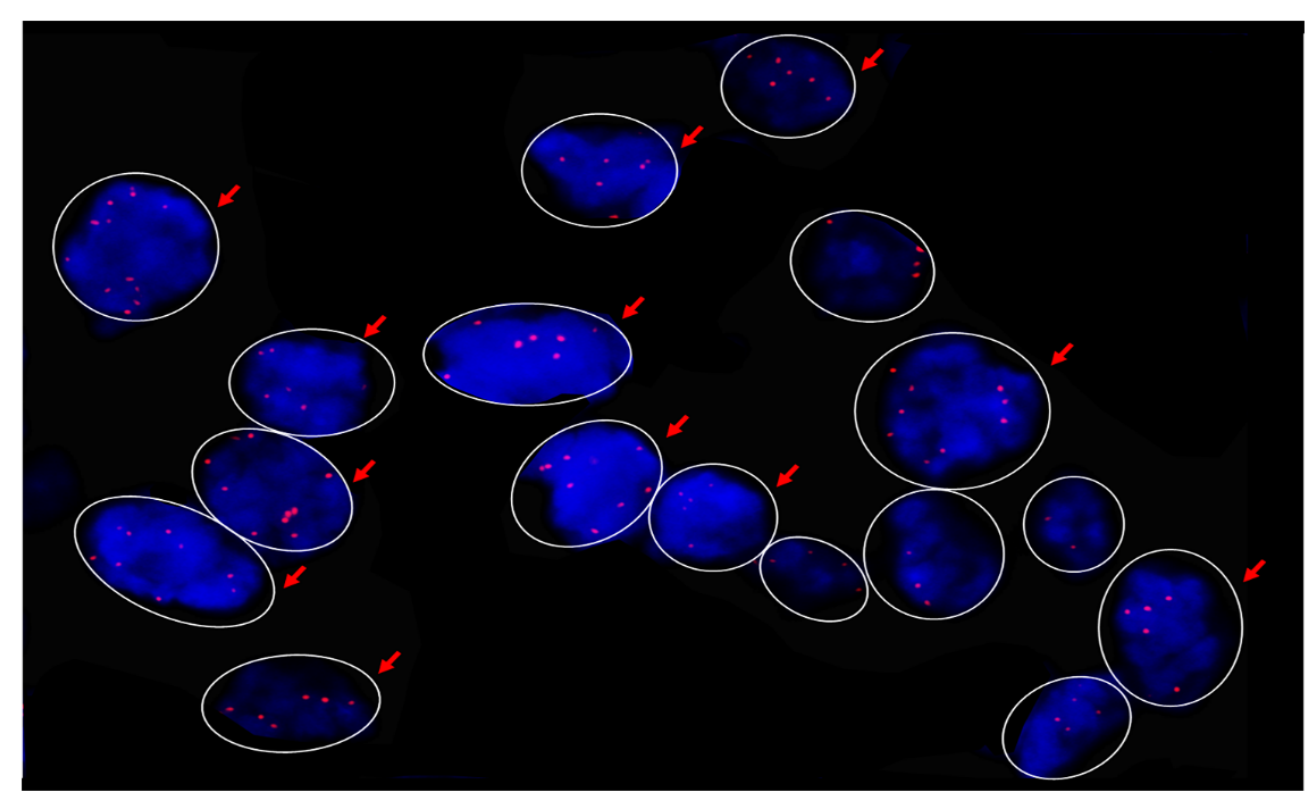

Figure 1. FISH detecting signals within the 8q24.21 locus in a sebaceous carcinoma from Case 8 . Arrows indicate nuclei with five or more MYC signals.

\subsection{MYC Immunohistochemistry}

We next examined the expression of MYC protein in all sebaceous carcinomas that were subject to NGS, as well as four additional OA tumors, using immunohistochemistry. Sebaceous carcinomas with and without MYC copy gain demonstrating a range of expression are shown in Figure 2. Neoplastic sebaceous glands (136.3 \pm 37.4$)$ had significantly greater h scores $(p \leq 0.001)$ compared to adjacent normal glands $(41.7 \pm 12.7)$. High levels of protein expression (MYC $\mathrm{h}$ scores $\geq 100$ ) tended to occur more commonly in OA tumors than extraocular tumors. There was no correlation between MYC copy gain and MYC immunolabeling $(p=1.00)$, tumor size $(p=0.50)$ or concomitant mutations in TP53 or RB1 $(p=1.00)$ (see Table 4$)$.

Table 4. MYC CNV status in sebaceous carcinoma and its relationship to MYC protein expression, tumor size, and tumor suppressor mutations.

\begin{tabular}{|c|c|c|c|c|}
\hline Variable & $\begin{array}{c}\text { All Cases } \\
\begin{array}{c}(n=11) \\
n(\%)\end{array}\end{array}$ & $\begin{array}{c}\text { No MYC Copy } \\
\text { Gain } \\
(n=3) \\
n(\%)\end{array}$ & $\begin{array}{c}\text { MYC Copy } \\
\text { Gain } \\
(n=8) \\
n(\%)\end{array}$ & $p$ Value \\
\hline \multicolumn{5}{|l|}{$\begin{array}{l}\text { MYC expression } \\
\text { (IHC) }\end{array}$} \\
\hline Low & $5(45)$ & $1(33)$ & $4(50)$ & \multirow{2}{*}{1.00} \\
\hline High & $6(55)$ & $2(67)$ & $4(50)$ & \\
\hline $\begin{array}{l}\text { Tumor size }(\mathbf{m m}) \\
\text { mean } \pm S D\end{array}$ & $7.7 \pm 2.6$ & $6.5 \pm 0.7$ & $8.0 \pm 2.9$ & 0.50 \\
\hline \multicolumn{5}{|l|}{ TP53 } \\
\hline Mutation & $8(73)$ & $2(67)$ & $6(75)$ & \multirow[t]{2}{*}{1.00} \\
\hline WT & $3(27)$ & $1(33)$ & $2(25)$ & \\
\hline \multicolumn{5}{|l|}{$R B 1$} \\
\hline Mutation & $6(55)$ & $2(67)$ & $4(50)$ & \multirow[t]{2}{*}{1.00} \\
\hline WT & $5(45)$ & $1(33)$ & $4(50)$ & \\
\hline
\end{tabular}

MYC expression was also evaluated in two common laboratory strains of mice. In both strains, MYC was localized to the basilar epithelial layers of the Meibomian glands, as shown in Figure 3. 


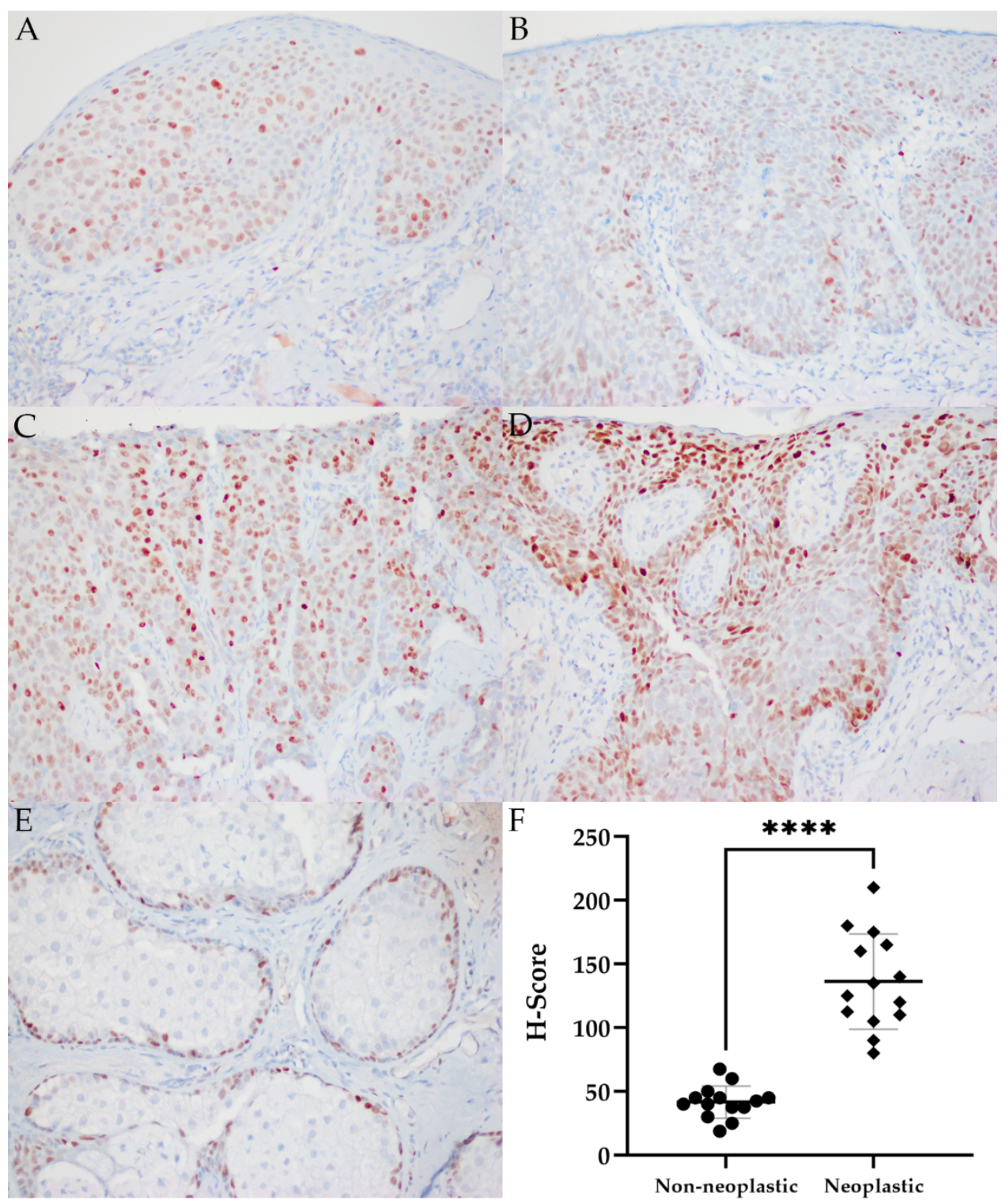

Figure 2. MYC immunohistochemistry of intraepithelial sebaceous carcinomas without MYC copy gain in Case 10 (A) and Case 3 (B) and with MYC copy gain in Case 4 (C) and Case 6 (D). Representative image of non-neoplastic sebaceous glands with MYC immunolabeling of basal cells (E). H scores for neoplastic sebaceous glands were significantly greater than those for non-neoplastic sebaceous glands. Data are shown as mean $\pm \mathrm{SD}\left({ }^{* * * *} p \leq 0.0001\right)(\mathbf{F})$. 


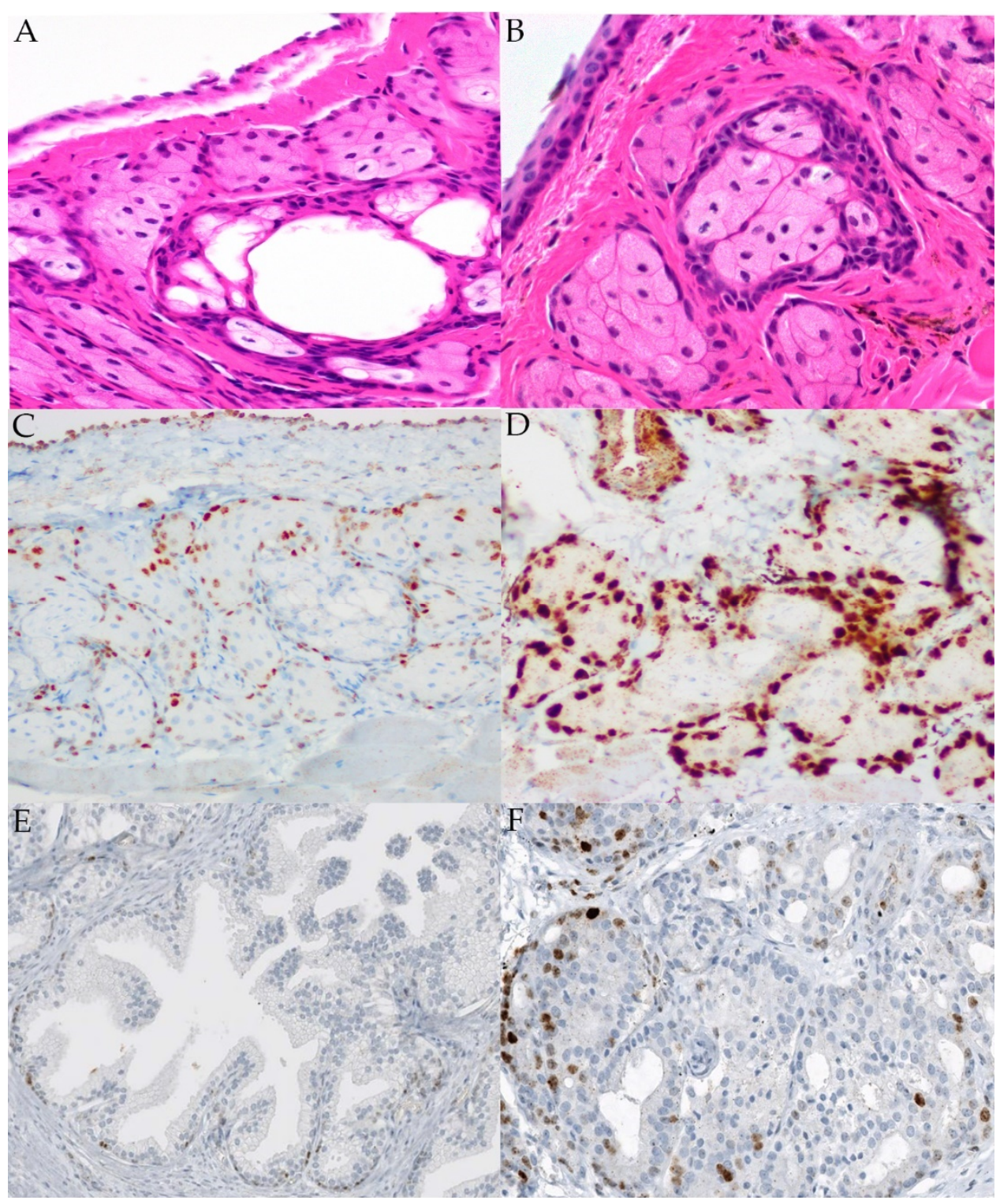

Figure 3. H\&E staining and MYC immunolabeling of CD1 (A,C) and C57B6 (B,D) murine eyelid. Controls included normal prostatic glandular epithelium (E) and prostatic adenocarcinoma (F).

\section{Discussion}

Somatic TP53 and RB1 mutations are among the most frequently reported in sebaceous carcinomas. In this cohort, $77 \%$ and $54 \%$ of all sebaceous carcinomas harbored these mutations, respectively. TP53 mutations were only identified in OA tumors, and the frequency in our group was similar to that reported in prior studies $[11,24,35]$. One previous study reported aberrant immunolabeling, potentially corresponding to TP53 mutations in 19/29 (66\%) of OA sebaceous carcinomas; in another series, TP53 mutations were detected in 23/31 (71\%) of cases [11,35]. Additionally, overexpression of Has-miR-34a, part of the TP53 suppressor complex, has been reported in both nodular and pagetoid sebaceous carcinomas, and nuclear expression has been observed in $68 \%$ of intraepithelial tumor cells in OA cases [10,22]. RB1 mutations were reported in 14/29 $(48 \%)$ and 12/31 $(39 \%)$ of OA tumors in two studies [11,35].

NOTCH1 alterations were present in 33\% of all sebaceous carcinomas in the present study, with indels observed in $2 / 2$ of OA and $1 / 2$ extraocular tumors harboring a mutation. $\mathrm{NOTCH}$ family mutations have been reported in OA metastases and primary extraocular sebaceous carcinomas in one study, and 8/31 (26\%) of tumors harbored NOTCH1 mutations 
in another $[24,35]$. In both of these series, NOTCH1 mutations occurred concomitantly with TP53 and RB1 mutations in the majority of cases [24,35]. Here, $2 / 2$ of the OA tumors with NOTCH1 mutations were also TP53/RB1 double mutants, while neither of the extraocular tumors with NOTCH1 mutations had either TP53 or RB1 mutations. Interestingly, one study concluded that OA sebaceous carcinomas with TP53 and/or RB1 mutations with concurrent $\mathrm{NOTCH}$ family mutations correlated with older patient populations, higher tumor grades, and a greater propensity for tumor recurrence [11].

Notch signaling has been shown to act as a molecular switch in the skin, promoting epidermal differentiation, and NOTCH1 ablation results in epidermal hyperproliferation [36,37]. Loss of function in Notch signaling alters sebaceous gland differentiation with a reduction of mature sebocyte density, while conditional NOTCH1 deletion results in sebaceous gland atrophy [38-40]. Mice with pharmacologic inhibition or deficiency of $\gamma$-secretase show both disrupted sebaceous gland development and epidermal hyperproliferations with squamous cell carcinomas of the head and neck, respectively, supporting a pleotropic role for Notch in epithelial tissues [41,42].

A potential epigenetic driver of sebaceous carcinoma was observed in the current study, as 4/12 (25\%) of all sebaceous carcinomas harbored mutations in KMT2C, or lysine methyltransferase $2 \mathrm{C}$, with $2 / 2$ OA tumors harboring missense mutations and $2 / 2$ extraocular tumors harboring deletions. KMT2C serves as one of the key regulators of H3K4 methylation, and inactivation results in the development of ureteral neoplasms in mice. It has been reported in breast tumors, glioblastomas, melanoma, and pancreatic cancer in human patients [43-45]. Also referred to as MLL3, KMT2C is a component of the activating signal cointegrator complex, with overexpression documented in a number of epithelial neoplasms [44,46,47]. Mutations in KMT2D (MLL2), a closely related methyltransferase, have been identified in squamous cell carcinomas and reported in sebaceous carcinomas with a UV damage mutational signature $[33,48]$. In another study, an extraocular sebaceous carcinoma harbored a mutation in $M L L 3$, while one primary and one metastatic OA harbored mutations in MLL2 [24].

Previous studies have utilized sequencing approaches to better characterize molecular drivers in sebaceous carcinoma, with one reporting a low incidence of tumors (12/32) harboring more than $5 \mathrm{CNV}$ events, and the most common event resulting from a single copy loss of chromosome 17p, where TP53 is located [24,33,35]. The current study did not identify high level copy gains in any tumor, consistent with previous findings; however, $54 \%$ of tumors harbored equivocal copy gains, and $18 \%$ demonstrated copy gains suggestive of amplification in MYC [33]. Expression of MYC in the basal layers of the epidermis and the proliferative zone at the base of hair follicles has been reported [49,50]. Additionally, growth factor-induced MYC promoter activity has been demonstrated in proliferating keratinocytes, while MYC knockdown inhibits this proliferation [51,52]. Despite a clear oncogenic role, MYC can also stimulate both terminal differentiation of keratinocytes and sebocytes, and in overexpressing transgenic models, induce division of differentiated cells, leading to benign or pre-malignant proliferation [49,53-56].

Additional studies have demonstrated sebaceous gland hyperplasia in Blimp1-ablated mice, mediated by loss of $c-m y c$ repression, and decreased sebocyte size and density with c-myc inhibition in Blimp1+- induced sebaceous gland organoids [57-59]. With respect to epithelial neoplasms, MYC amplification has been reported in approximately $50 \%$ of squamous cell carcinomas from immunosuppressed patients following organ transplantation, and diffuse nuclear MYC immunolabeling has been demonstrated in eyelid sebaceous carcinomas [60,61]. Additionally, overexpressed MYC targets of miRNAs have been reported in sebaceous carcinomas with pagetoid features [22].

Due to the relative frequency of $M Y C$ copy gains in this study, and the well-documented regulatory role for $M Y C$ in epithelial and sebaceous development, additional evaluation of tumors by FISH and immunohistochemistry was pursued to confirm copy number gains and characterize the potential contribution of $M Y C$ to sebaceous oncogenesis. FISH identified $4-5$ or more signals at $8 \mathrm{q} 24$ per nucleus in $70-76 \%$ of tumor cells in the two 
samples with copy gains suggestive of MYC amplification by NGS, confirming unequivocal amplification [62]. Similar to previous studies, immunohistochemical analysis of sebaceous carcinomas demonstrated increased MYC labeling of nuclei within intraepithelial and subepithelial tumor cells compared to absent to weak labeling of adjacent normal basilar epidermal, conjunctival, and sebaceous cells [61]. However, there was no correlation between MYC protein expression as measured by h score and mean MYC mean $\log _{2}$ copy ratio, suggesting that gain of copy does not consistently yield increased levels of MYC protein, or that other mechanisms are driving increased MYC expression. Overall, however, the neoplastic epithelial immunolabeling supports a role for $M Y C$ in the formation and malignant progression of these tumors.

Ocular adnexal sebaceous carcinomas, arising from Meibomian glands, glands of Zeis, and sebaceous glands of eyelid skin tend toward a poorly differentiated and more aggressive phenotype. They are reported to be more common in the upper lid where there is a higher density of Meibomian glands [23,63]. The histomorphologic features of sebaceous glands from tamoxifen-inducible $c M Y C$ mice are well documented, and a few studies have identified $M Y C$ as a differentially expressed transcription factor and potential therapeutic target in Meibomian gland dysfunction [64-70]. However, few studies interrogating MYC expression in normal Meibomian glands have been published. To further evaluate MYC expression in the normal Meibomian gland, we pursued characterization in two mouse strains: CD1 and C57B6. In contrast to the reported paucity of nuclear staining in normal eyelid sebaceous glands in humans, strong immunolabeling of MYC was observed in the proliferating cells of the outer layer of the Meibomian gland in both mouse strains [61]. Interestingly, MYC expression in the basal cells of the epidermis and sebaceous glands in these two mouse strains is consistent with previous immunolabeling studies in human skin $[49,50]$.

In summary, our data support the importance of p53 and $\mathrm{Rb}$ in sebaceous carcinoma, and also identify a number of other potential oncogenic drivers, including copy number gains at the MYC locus. Our study is limited by the relatively low number of cases successfully sequenced, and the fact that only two extraocular tumors were examined limits statistical comparisons with OA tumors. Additionally, low tumor cellularity also likely contributed to the underestimation of copy gains of the MYC locus in these cases. Nevertheless, further evaluation of MYC gains in tumors, as well as its role in the developing Meibomian gland, may support its role in sebaceous neoplasia [71]. In addition. immunohistochemical or molecular analyses of p53, Rb, Notch1, and MLL3 or its downstream target, H3K4, could also advance our understanding of their pathogenicity in OA sebaceous carcinoma. Future multi-center studies may provide larger numbers of samples and allow more statistical analyses of NGS and other molecular data, as well as additional clinical correlation.

\section{Materials and Methods}

\subsection{Study Design}

Study approval was obtained from the Internal Review Board at our institution. We performed a retrospective search through the Surgical Pathology and Ophthalmic Pathology Archives of The Johns Hopkins Hospital for cases of both OA and extraocular sebaceous carcinoma between 2003-2021. The electronic medical record was reviewed for clinical and pathologic information: Age at presentation, gender, ethnicity, history of malignancy, tumor location, intraepithelial involvement, tumor size, and TNM staging. All cases were reviewed to confirm the diagnosis and determine the amount of tissue remaining. Staging was performed according to the American Joint Committee on Cancer (AJCC) TNM staging system for eyelid carcinoma, 8th edition guidelines.

\subsection{DNA Extraction and Next-Generation Sequencing}

Manual microdissection of FFPE tissue sections followed by DNA extraction and nextgeneration sequencing (NGS) was performed in the Johns Hopkins Molecular Diagnostic Laboratory using standard clinical protocols and the UCSC version hg19 (NCBI build 
GRCh37) human reference sequence genome assembly. The Solid Tumor Panel used 435 cancer-related genes, and a complete list can be found in (https:/ / pathology.jhu.edu/jhmlservices/assets/test-directory/SolidTumorPanel-II_GeneList_v5.0.pdf; accessed 1 December 2020). Sequences were examined for point mutations and small insertion/deletion mutations in all 435 loci, while for 64 of these copy number variations (CNVs) were also reported.

Thirteen sebaceous carcinomas were subject to NGS — with all, but Case $2(12 / 13)$, meeting laboratory quality control thresholds. In one sample (Case 11) DNA concentration was sufficient only for a smaller clinical panel of 27 cancer genes (see Supplementary Materials).

\subsection{MYC Fluorescence In Situ Hybridization}

Fluorescence in situ hybridization for the MYC 8q24.21 rearrangement was performed on FFPE sections of select OA sebaceous carcinomas $(n=2)$ by the Johns Hopkins Cytogenetics Laboratory using standard CLIA approved clinical protocols. The threshold for low level copy number gains suggestive of $M Y C$ amplification was 5 signals per nuclei.

\subsection{MYC Immunohistochemistry}

Immunolabeling of FFPE sections of all specimens utilized for NGS was performed by the Department of Pathology clinical laboratory using $5 \mu \mathrm{m}$ sections with a recombinant anti-c-Myc antibody (Abcam ab32072, clone Y69, dilution 1:400; Cambridge, UK) using the Ventana benchmark Ultra platform, ultraView kit (Tucson, AZ, USA), and standard protocols. In human studies, high MYC lymphoma was used as a positive control, while primary antibody was removed in negative controls. Specimens were scored as having no (0), weak (1), moderate (2), or strong (3) immunoreactivity, and the percentage of tumor cells staining was recorded. An h-score was calculated by multiplying the staining intensity score by the percentage (by decile) of positively-labeled tumor cells (or non-neoplastic sebaceous gland). Low h-scores were designated 0-99, and an h score of 100-300 was designated as high. Immunohistochemical scoring was performed independently by two pathologists (CP and CGE).

Eyelids from normal adult cadaveric C57B6 and CD1 mice (Charles River, Wilmington, MA, USA) were dissected and fixed in $10 \% \mathrm{NBF}$ for $72 \mathrm{~h}$ at room temperature. Samples were processed, paraffin-embedded, sectioned, and stained with hematoxylin and eosin (H\&E) by the JHMI Reference Histology Laboratory using standard protocols. Immunohistochemical analysis was performed on tissue sections using MYC (rabbit monoclonal, clone EP121, Epitomics, 1:600; St. Louis, MO, USA) as previously described [72]. In the murine studies, normal prostatic glandular epithelium and prostatic adenocarcinoma were used as negative and positive controls.

\subsection{Statistical Analyses}

Correlation of MYC mean $\log _{2}$ ratio with clinicopathologic features, including gender, age at presentation, tumor location, and laterality, MYC h score, and concomitant somatic mutations, was analyzed by Fisher's exact test and two-tailed $t$-tests. H scores for neoplastic and non-neoplastic sebaceous glands were evaluated using a Student's t-test. All statistical analyses were performed using Prism 8 GraphPad (v. 9.2.0; San Diego, CA, USA) $(\alpha=0.05)$.

\section{Conclusions}

We have demonstrated equivocal copy gains of MYC in 54\% and low-level gains suggestive of amplification in $18 \%$ of sebaceous carcinomas, with the latter confirmed by FISH. Further work is necessary to elucidate the role of MYC in sebaceous oncogenesis; however, these results indicate it may present a target for precision therapy. A high frequency of mutations in tumor suppressors, including TP53 and RB1, with concurrent NOTCH1 computations were reported here in addition to both missense mutations and deletions in KMT2C in OA and extraocular sebaceous carcinomas, respectively. Identifying 
genetic and epigenetic mutations and resulting dysregulated cellular pathways as potential targets for personalized treatment of aggressive OA sebaceous carcinomas could facilitate early and more definitive clinical management, prolonging survival and minimizing the need for radical surgical dissections.

Supplementary Materials: The following are available online at https: / www.mdpi.com/article / 10.3390 /ijms22168454/s1, Figure S1: Frequency of genes with equivocal copy number gains. NGS Solid Tumor Panel-Limited Methodology for Case 11.

Author Contributions: Conceptualization, C.G.E. and A.A.C.; Methodology, A.M.D.M. and J.L.H.; Formal Analysis, Y.Z., L.A.M., C.G.E., A.A.C., and C.P.; Data Curation, A.A.C., R.M., C.P., and C.G.E.; Writing-Original Draft Preparation, C.P.; Writing-Review and Editing, C.P., C.G.E., Y.Z., and L.A.M. and A.A.C.; Supervision, C.G.E., A.M.D.M., and A.A.C.; Funding Acquisition, A.A.C. All authors have read and agreed to the published version of the manuscript.

Funding: This research was funded by an ASOPRS Foundation Grant.

Institutional Review Board Statement: This study was conducted according to the guidelines in the Declaration of Helsinki, and approved by the Institutional Review Board of Johns Hopkins University (IRB00196130, 3/12/2019).

Informed Consent Statement: Informed consent was obtained from all subjects involved in the study.

Conflicts of Interest: The authors declare no conflict of interest.

\section{References}

1. Orr, C.; Yazdanie, F.; Shinder, R. Current review of sebaceous cell carcinoma. Curr. Opin. Ophthalmol. 2018, 29, 445-450. [CrossRef]

2. Dasgupta, T.; Wilson, L.; Yu, J. A retrospective review of 1349 cases of sebaceous carcinoma. Cancer 2009, 115, 158-165. [CrossRef]

3. Shields, J.; Demirci, H.; Marr, B.; Eagle, R., Jr.; Shields, C. Sebaceous carcinoma of the eyelids: Personal experience with 60 cases. Ophthalmology 2004, 111, 2151-2157. [CrossRef]

4. Shields, J.; Saktanasate, J.; Lally, S.; Carrasco, J.; Shields, C. Sebaceous carcinoma of the ocular region: The 2014 professor Winifred Mao lecture. Asia Pac. J. Ophthalmol. 2015, 4, 221-227. [CrossRef] [PubMed]

5. Hou, J.; Killian, J.; Baum, C.; Otley, C.; Roenigk, R.; Arpey, C.; Weaver, A.; Brewer, J. Characteristics of sebaceous carcinoma and early outcomes of treatment using Mohs micrographic surgery versus wide local excision: An update of the Mayo clinic experience over the past 2 decades. Derm. Surg. 2014, 40, 241-246. [CrossRef]

6. Stagner, A.; Jakobiec, F. Updates on the molecular pathology of selected ocular and ocular adnexal tumors: Potential targets for future therapy. Semin. Ophthalmol. 2016, 31, 188-196. [CrossRef]

7. Shalin, S.C.; Lyle, S.; Calonje, E.; Lazar, A.J.F. Sebaceous neoplasia and the Muir-Torre syndrome: Important connections with clinical implications. Histopathology 2010, 56, 133-147. [CrossRef] [PubMed]

8. Sa, H.-S.; Rubin, M.L.; Xu, S.; Ning, J.; Tetzlaff, M.; Sagiv, O.; Kandl, T.J.; Esmaeli, B. Prognostic factors for local recurrence, metastasis and survival for sebaceous carcinoma of the eyelid: Observations in 100 patients. Br. J. Ophthalmol. 2019, $103,980$. [CrossRef]

9. Tripathi, R.; Chen, Z.; Li, L.; Bordeaux, J.S. Incidence and survival of sebaceous carcinoma in the United States. J. Am. Acad. Derm. 2016, 75, 1210-1215. [CrossRef]

10. Bell, W.; Singh, K.; Rajan, A.; Eberhart, C. Expression of P16 and P53 in intraepithelial periocular sebaceous carcinoma. Ocul. Oncol. Pathol. 2016, 2, 71-75. [CrossRef]

11. Tetzlaff, M.; Curry, J.; Ning, J.; Sagiv, O.; Kandi, T.; Peng, B.; Bell, D.; Routbort, M.; Hudgens, C.; Ivan, D.; et al. Distinct biological types of ocular adnexal sebaceous carcinoma: HPV-driven and virus-negative tumors arise through nonoverlapping molecular-genetic alterations. Clin. Cancer Res. 2019, 15, 1280-1290. [CrossRef] [PubMed]

12. Kiyosaki, K.; Nakada, C.; Hijiya, N.; Tsukamoto, Y.; Matsuura, K.; Nakatsuka, K.; Daa, T.; Yokoyama, S.; Imaizumi, M.; Moriyama, M. Analysis of P53 mutations and the expression of P53 and P21WAF1/CIP1protein in 15 cases of sebaceous carcinoma of the eyelid. Investig. Opthalmol. Vis. Sci. 2010, 51, 7. [CrossRef]

13. Singh, G.; Weinstock, B.; Wu, A. Clinical and immunohistochemical features of sebaceous carcinoma: Focusing on the P53 tumor suppressor. J. Clin. Exp. Ophthalmol. 2017, 8, 1. [CrossRef]

14. Cabral, E.S.; Auerbach, A.; Killian, J.K.; Barrett, T.L.; Cassarino, D.S. Distinction of benign sebaceous proliferations from sebaceous carcinomas by immunohistochemistry. Am. J. Dermatol. 2006, 28, 465-471. [CrossRef]

15. Ali-Ridha, A.N.; Brownstein, S.; Jiang, K.; Milman, T.; Burns, B.; Blanco, P.; Farmer, J. Immunohistochemical analysis of sebaceous cell carcinoma in comparison to both basal cell carcinoma and squamous cell carcinoma. Investig. Ophthalmol. Vis. Sci. 2014, 55, 5432.

16. Bao, Y.; Selfridge, J.E.; Wang, J.; Zhao, Y.; Cui, J.; Guda, K.; Wang, Z.; Zhu, Y. Mutations in TP53, ZNF750, and RB1 typify ocular sebaceous carcinoma. J. Genet. Genom. 2019, 46, 315-318. [CrossRef] 
17. Shalin, S.C.; Sakharpe, A.; Lyle, S.; Lev, D.; Calonje, E.; Lazar, A.J. P53 staining correlates with tumor type and location in sebaceous neoplasms. Am. J. Dermatopathol. 2012, 34, 129-138. [CrossRef]

18. Gonzalez-Fernandez, F.; Kaltreider, S.A.; Patnaik, B.D.; Retief, J.D.; Bao, Y.; Newman, S.; Stoler, M.H.; Levine, P.A. Sebaceous carcinoma: Tumor progression through mutational inactivation of P53. Ophthalmology 1998, 105, 497-506. [CrossRef]

19. Hussain, R.; Matthews, J.; Dubovy, S.; Thompson, J.; Wang, G. UV-independent P53 mutations in sebaceous carcinoma of the eyelid. Ophthalmic Plast. Reconstr. Surg. 2014, 30, 392-395. [CrossRef]

20. Buitrago-Pérez, A.; Garaulet, G.; Vázquez-Carballo, A.; Paramio, J.M.; García-Escudero, R. Molecular signature of HPV-induced carcinogenesis: PRb, P53 and gene expression profiling. Curr. Genom. 2009, 10, 26-34. [CrossRef]

21. Moore, R.; Zhang, X.; Allison, D.; Rooper, L.; Campbell, A.; Eberhart, C. High-risk human papillomavirus and ZEB1 in ocular adnexal sebaceous carcinoma. J. Cutan. Pathol. 2021, 48, 1027-1033. [CrossRef]

22. Bladen, J.; Wang, J.; Sangaralingam, A.; Moosajee, M.; Fitchett, C.; Chelala, C.; Beaconsfield, M.; O'Toole, E.; Philpott, M.; Ezra, D. MicroRNA and transcriptome analysis in periocular sebaceous gland carcinoma. Sci. Rep. 2018, 8, 7531. [CrossRef]

23. Mulay, K.; Aggarwal, E.; White, V. Periocular sebaceous gland carcinoma: A comprehensive review. Saudi J. Ophthalmol. 2013, 27, 159-165. [CrossRef] [PubMed]

24. Tetzlaff, M.; Singh, R.; Seviour, E.; Curry, J.; Hudgens, C.; Bell, D.; Wimmer, D.; Ning, J.; Czerniak, B.; Zhang, L.; et al. Nextgeneration sequencing identifies high frequency of mutations in potentially clinically actionable genes in sebaceous carcinoma. $J$. Pathol. 2016, 240, 84-95. [CrossRef] [PubMed]

25. Tomonari, M.; Shimada, M.; Nakada, Y.; Yamamoto, I.; Itoh, M.; Koike, Y.; Kobayashi, A.; Miki, J.; Yamada, H.; Kimura, T.; et al. Muir-Torre syndrome: Sebaceous carcinoma concurrent with colon cancer in a kidney transplant recipient. A case report. BMC Nephrol. 2019, 20, 394. [CrossRef]

26. Marazza, G.; Masouyé, I.; Taylor, S.; Prins, C.; Gaudin, T.; Saurat, J.-H.; French, L.E. An illustrative case of Muir-Torre syndrome. Arch. Dermatol. 2006, 142, 1039-1042. [CrossRef]

27. Hare, H.H.; Mahendraker, N.; Sarwate, S.; Tangella, K. Muir-Torre syndrome: A rare but important disorder. Cutis 2008, 82, 252-256.

28. Chen, Q.; Wang, M.; Xu, Z.; Wang, M.; Jin, S.; Tian, S.; Xiao, S. Muir-Torre syndrome with a frame-shift mutation in the MSH2 gene: A rare case report and literature review. Int. J. Gynecol. Pathol. 2020, 39, 136-140. [CrossRef]

29. Suspiro, A.; Fidalgo, P.; Cravo, M.; Albuquerque, C.; Ramalho, E.; Leitão, C.N.; Costa Mira, F. The Muir-Torre syndrome: A rare variant of hereditary nonpolyposis colorectal cancer associated with HMSH2 mutation. Am. J. Gastroenterol. 1998, 93, 1572-1574. [CrossRef]

30. Perera, S.; Ramyar, L.; Mitri, A.; Pollett, A.; Gallinger, S.; Speevak, M.D.; Aronson, M.; Bapat, B. A novel complex mutation in MSH2 contributes to both Muir-Torre and Lynch syndrome. J. Hum. Genet. 2010, 55, 37-41. [CrossRef]

31. Morales-Burgos, A.; Sánchez, J.L.; Figueroa, L.D.; De Jesús-Monge, W.E.; Cruz-Correa, M.R.; González-Keelan, C.; Nazario, C.M. MSH-2 and MLH-1 protein expression in Muir Torre syndrome-related and sporadic sebaceous neoplasms. P. R. Health Sci. J. 2008, 27, 322-327.

32. Entius, M.M.; Keller, J.J.; Drillenburg, P.; Kuypers, K.C.; Giardiello, F.M.; Offerhaus, G.J. Microsatellite instability and expression of HMLH-1 and HMSH-2 in sebaceous gland carcinomas as markers for Muir-Torre syndrome. Clin. Cancer Res. 2000, 6, 1784-1789.

33. North, J.; Golovato, J.; Vaske, C.; Sanborn, J.; Nguyen, A.; Wu, W.; Goode, B.; Stevers, M.; McMullen, K.; Perez White, B.; et al. Cell of origin and mutation pattern define three clinically distinct classes of sebaceous carcinoma. Nat. Commun. 2018, 9, 1894. [CrossRef] [PubMed]

34. Meric-Bernstam, F.; Johnson, A.; Holla, V.; Bailey, A.M.; Brusco, L.; Chen, K.; Routbort, M.; Patel, K.P.; Zeng, J.; Kopetz, S.; et al. A decision support framework for genomically informed investigational cancer therapy. J. Natl. Cancer Inst. 2015, 107, djv098 [CrossRef]

35. Xu, S.; Moss, T.; Rubin, M.; Ning, J.; Eterovic, A.; Yu, H.; Jia, R.; Fan, X.; Tetzlaff, M.; Esmaeli, B. Whole-exome sequencing for ocular adnexal sebaceous carcinoma suggests PCDH15 as a novel mutation associated with metastasis. Mod. Pathol. 2020, 33, 1256-1263. [CrossRef]

36. Gratton, R.; Tricarico, P.; Moltrasio, C.; Lima Estevão de Oliveira, A.; Brandão, L.; Marzano, A.; Zupin, L.; Crovella, S. Pleiotropic role of notch signaling in human skin diseases. Int. J. Mol. Sci. 2020, 21, 4214. [CrossRef] [PubMed]

37. Blanpain, C.; Lowry, W.; Pasolli, H.; Fuchs, E. Canonical notch signaling functions as a commitment switch in the epidermal lineage. Genes Dev. 2006, 20, 3022-3035. [CrossRef] [PubMed]

38. Aubin-Houzelstein, G. Notch signaling and the developing hair follicle. Adv. Exp. Med. Biol. 2012, 727, 142-160. [CrossRef]

39. Zhang, Y.; Lam, O.; Nguyen, M.-T.T.; Ng, G.; Pear, W.S.; Ai, W.; Wang, I.-J.; Kao, W.W.-Y.; Liu, C.-Y. Mastermind-like transcriptional co-activator-mediated notch signaling is indispensable for maintaining conjunctival epithelial identity. Development 2013, 140, 594. [CrossRef] [PubMed]

40. Lin, H.-Y.; Kao, C.-H.; Lin, K.-C.; Kaartinen, V.; Yang, L.-T. Notch signaling regulates late-stage epidermal differentiation and maintains postnatal hair cycle homeostasis. PLoS ONE 2011, 6, e15842. [CrossRef]

41. Pan, Y.; Lin, M.-H.; Tian, X.; Cheng, H.-T.; Gridley, T.; Shen, J.; Kopan, R. $\gamma$-Secretase functions through notch signaling to maintain skin appendages but is not required for their patterning or initial morphogenesis. Dev. Cell 2004, 7, 731-743. [CrossRef] [PubMed] 
42. Li, T.; Wen, H.; Brayton, C.; Das, P.; Smithson, L.A.; Fauq, A.; Fan, X.; Crain, B.J.; Price, D.L.; Golde, T.E.; et al. Epidermal growth factor receptor and notch pathways participate in the tumor suppressor function of $\gamma$-secretase. J. Biol. Chem. 2007, 282, 32264-32273. [CrossRef]

43. Kumar, A.; Kumari, N.; Nallabelli, N.; Prasad, R. Pathogenic and therapeutic role of H3K4 family of methylases and demethylases in cancers. Indian J. Clin. Biochem. 2019, 34, 123-132. [CrossRef]

44. Lee, J.; Kim, D.-H.; Lee, S.; Yang, Q.-H.; Lee, D.; Lee, S.-K.; Roeder, R.; Lee, J. A Tumor suppressive coactivator complex of P53 containing ASC-2 and histone H3-lysine-4 methyltransferase MLL3 or its paralogue MLL4. Proc. Natl. Acad. Sci. USA 2009, 106, 8513-8518. [CrossRef] [PubMed]

45. Kudithipudi, S.; Jeltsch, A. Role of somatic cancer mutations in human protein lysine methyltransferases. Biochim. Biophys. Acta BBA Rev. Cancer 2014, 1846, 366-379. [CrossRef]

46. Weirich, S.; Kudithipudi, S.; Kycia, I.; Jeltsch, A. Somatic cancer mutations in the MLL3-SET domain alter the catalytic properties of the enzyme. Clin. Epigenet. 2015, 7, 36. [CrossRef] [PubMed]

47. Kim, S.-W.; Cheong, C.; Sohn, Y.-C.; Goo, Y.-H.; Oh, W.; Park, J.; Joe, S.; Kang, H.-S.; Kim, D.-K.; Kee, C.; et al. Multiple developmental defects derived from impaired recruitment of ASC-2 to nuclear receptors in mice: Implication for posterior lenticonus with cataract. Mol. Cell. Biol. 2002, 22, 8409-8414. [CrossRef]

48. Lin, D.-C.; Hao, J.-J.; Nagata, Y.; Xu, L.; Shang, L.; Meng, X.; Sato, Y.; Okuno, Y.; Varela, A.M.; Ding, L.-W.; et al. Genomic and molecular characterization of esophageal squamous cell carcinoma. Nat. Genet. 2014, 46, 467-473. [CrossRef]

49. Watt, F.M.; Frye, M.; Benitah, S.A. MYC in mammalian epidermis: How can an oncogene stimulate differentiation? Nat. Rev. Cancer 2008, 8, 234-242. [CrossRef]

50. Bull, J.J.; Miller-Röver, S.; Patel, S.V.; Chronnell, C.M.T.; McKay, I.A.; Philpott, M.P. Contrasting localization of c-Myc with other Myc superfamily transcription factors in the human hair follicle and during the hair growth cycle. J. Investig. Dermatol. 2001, 116, 617-622. [CrossRef]

51. Coffey, R.J., Jr.; Bascom, C.C.; Sipes, N.J.; Graves-Deal, R.; Weissman, B.E.; Moses, H.L. Selective inhibition of growth-related gene expression in murine keratinocytes by transforming growth factor beta. Mol. Cell. Biol. 1988, 8, 3088-3093. [CrossRef]

52. Hashiro, M.; Matsumoto, K.; Okumura, H.; Hashimoto, K.; Yoshikawa, K. Growth inhibition of human keratinocytes by antisense C-Myc oligomer is not coupled to induction of differentiation. Biochem. Biophys. Res. Commun. 1991, 174, 287-292. [CrossRef]

53. Gandarillas, A.; Watt, F.M. C-Myc promotes differentiation of human epidermal stem cells. Genes Dev. 1997, 11, 2869-2882. [CrossRef]

54. Pelengaris, S.; Littlewood, T.; Khan, M.; Elia, G.; Evan, G. Reversible activation of c-Myc in skin: Induction of a complex neoplastic phenotype by a single oncogenic lesion. Mol. Cell 1999, 3, 565-577. [CrossRef]

55. Waikel, R.; Wang, X.; Roop, D. Targeted expression of c-Myc in the epidermis alters normal proliferation, differentiation and UV-B induced apoptosis. Oncogene 1999, 18, 4870-4878. [CrossRef]

56. Cottle, D.; Kretzschmar, K.; Schweiger, P.; Quist, S.; Gollnick, H.; Natsuga, K.; Aoyagi, S.; Watt, F. C-MYC-induced sebaceous gland differentiation is controlled by an androgen receptor/P53 axis. Cell Rep. 2013, 3, 427-441. [CrossRef]

57. Horsley, V.; O'Carroll, D.; Tooze, R.; Ohinata, Y.; Saitou, M.; Obukhanych, T.; Nussenzweig, M.; Tarakhovsky, A.; Fuchs, E. Blimp1 defines a progenitor population that governs cellular input to the sebaceous gland. Cell 2006, 126, 597-609. [CrossRef]

58. Fuchs, E. Skin stem cells: Rising to the surface. J. Cell Biol. 2008, 180, 273-284. [CrossRef]

59. Feldman, A.; Mukha, D.; Maor, I.; Sedov, E.; Koren, E.; Yosefzon, Y.; Shlomi, T.; Fuchs, Y. Blimp1+ cells generate functional mouse sebaceous gland organoids in vitro. Nat. Commun. 2019, 10, 2348. [CrossRef]

60. Boukamp, P. Non-melanoma skin cancer: What drives tumor development and progression? Carcinogenesis 2005, 26, 1657-1667. [CrossRef] [PubMed]

61. Kim, N.; Kim, J.; Choung, H.-K.; Lee, M.; Khwarg, S. Expression of Shh and Wnt signaling pathway proteins in eyelid sebaceous gland carcinoma: Clinicopathologic study. Investig. Ophthalmol. Vis. Sci. 2013, 54, 370-377. [CrossRef]

62. Martín-Subero, J.; Odero, M.; Hernandez, R.; Cigudosa, J.; Agirre, X.; Saez, B.; Sanz-García, E.; Ardanaz, M.; Novo, F.; Gascoyne, R.; et al. Amplification of IGH/MYC fusion in clinically aggressive IGH/BCL2-positive germinal center B-cell lymphomas. Genes Chromosom. Cancer 2005, 43, 414-423. [CrossRef]

63. Rao, N.A.; Hidayat, L.C.A.A.; McLean, L.C.I.W.; Zimmerman, L.E. Sebaceous carcinomas of the ocular adnexa: A clinicopathologic study of 104 cases, with five-year follow-up data. Hum. Pathol. 1982, 13, 113-122. [CrossRef]

64. Arnold, I.; Watt, F.M. C-Myc activation in transgenic mouse epidermis results in mobilization of stem cells and differentiation of their progeny. Curr. Biol. 2001, 11, 558-568. [CrossRef]

65. Braun, K.M. Manipulation of stem cell proliferation and lineage commitment: Visualisation of label-retaining cells in wholemounts of mouse epidermis. Development 2003, 130, 5241-5255. [CrossRef] [PubMed]

66. Bull, J.; Pelengaris, S.; Hendrix, S.; Chronnell, C.; Khan, M.; Philpott, M. Ectopic expression of C-Myc in the skin affects the hair growth cycle and causes an enlargement of the sebaceous gland. Br. J. Dermatol. 2005, 152, 1125-1133. [CrossRef]

67. Frye, M. Evidence that Myc activation depletes the epidermal stem cell compartment by modulating adhesive interactions with the local microenvironment. Development 2003, 130, 2793-2808. [CrossRef]

68. Ehrmann, C.; Schneider, M.R. Genetically modified laboratory mice with sebaceous glands abnormalities. Cell. Mol. Life Sci. 2016, 73, 4623-4642. [CrossRef] 
69. Ni, Q.; Zhao, J.; Gao, Y.; Qin, D.; Chen, X.; Ainiwaer, X. Prediction of potential drugs and targets based on meibomian gland dysfunction module classification to guide individualized treatment. J. Cell. Biochem. 2019, 120, 14813-14821. [CrossRef]

70. Lee, L. Novel Gene Biomarkers Associated with Meibomian Gland Dysfunction. Ph.D. Thesis, University of New South Wales, Sydney, Australia, 2016.

71. Tawfik, H.A.; Abdulhafez, M.H.; Fouad, Y.A.; Dutton, J.J. Embryologic and fetal development of the human eyelid. Ophthalmic Plast. Reconstr. Surg. 2016, 32, 407-414. [CrossRef] [PubMed]

72. Hubbard, G.K.; Mutton, L.N.; Khalili, M.; McMullin, R.P.; Hicks, J.L.; Bianchi-Frias, D.; Horn, L.A.; Kulac, I.; Moubarek, M.S.; Nelson, P.S.; et al. Combined MYC activation and Pten loss are sufficient to create genomic instability and lethal metastatic prostate cancer. Cancer Res. 2016, 76, 283. [CrossRef] [PubMed] 